\title{
Vinyl and Alkynyl Triazenes: Synthesis, Reactivity, and Applications
}

\author{
Abdusalom A. Suleymanov, ${ }^{[a]}$ and Kay Severin ${ }^{*[a]}$ \\ [a] Abdusalom A. Suleymanov, Prof. Dr. Kay Severin \\ Institut des Sciences et Ingénierie Chimiques, Ecole Polytechnique Fédérale de Lausanne (EPFL), 1015 Lausanne, Switzerland
}

E-mail: kay.severin@epfl.ch

\begin{abstract}
Aromatic compounds containing triazenyl groups $\left(\mathrm{N}_{3} \mathrm{RR}^{\prime}\right)$ have a profound impact on synthetic organic and medicinal chemistry. In contrast, the chemistry of vinyl and alkynyl triazenes was a largely uncharted territory until recently. The situation has changed over the last five years, and it has become apparent that vinyl and alkynyl triazenes are highly interesting compounds with a unique reactivity. The electron-donating properties of the triazenyl group provide alkynyl triazenes with an ynamide-like reactivity, which can be exploited in reactions of the triple bond. Vinyl triazenes, on the other hand, can be used for electrophilic vinylation reaction. The foundation for this new triazene chemistry are synthetic pathways, which allow preparing vinyl and alkynyl triazenes in few steps from readily available starting materials. In this Minireview, we summarize recent developments in this area.
\end{abstract}

\section{Introduction}

Aryl triazenes of the general formula $A r-N^{1}=N^{2}-N^{3} R R^{\prime}$ are known for more than 150 years, and the chemistry of these compounds has been described in several review articles and monographs (Scheme 1) ${ }^{[1]}$ In contrast, there were - until recently - only few reports about triazenes with vinyl groups attached to N1, and 1-alkynyl triazenes were unknown until 2015. In this Minireview, we discuss the chemistry of vinyl- and alkynyl triazenes. We will show that these compounds display a unique reactivity, and that they are highly attractive reagents for synthetic organic chemistry. But to set the stage, we would like to recap briefly some key properties and applications of aryl triazenes.

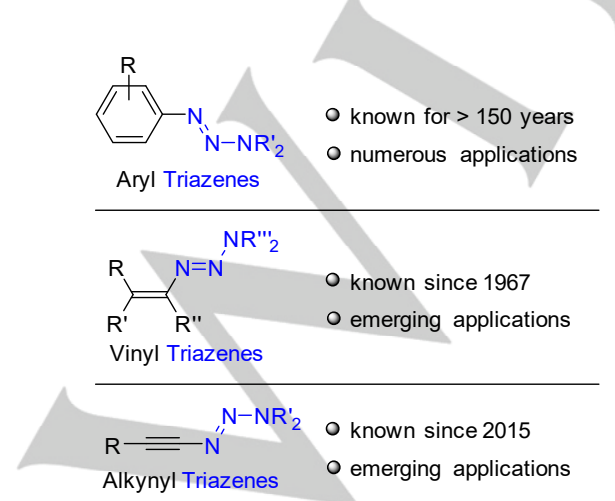

Scheme 1. 1-Aryl-, 1-vinyl-, and 1-alkynyl triazenes.
The most commonly used route for the synthesis of aryl triazenes is the diazotization of anilines, followed by reaction with primary or secondary amines (Scheme $2 \mathrm{~A}$ ).

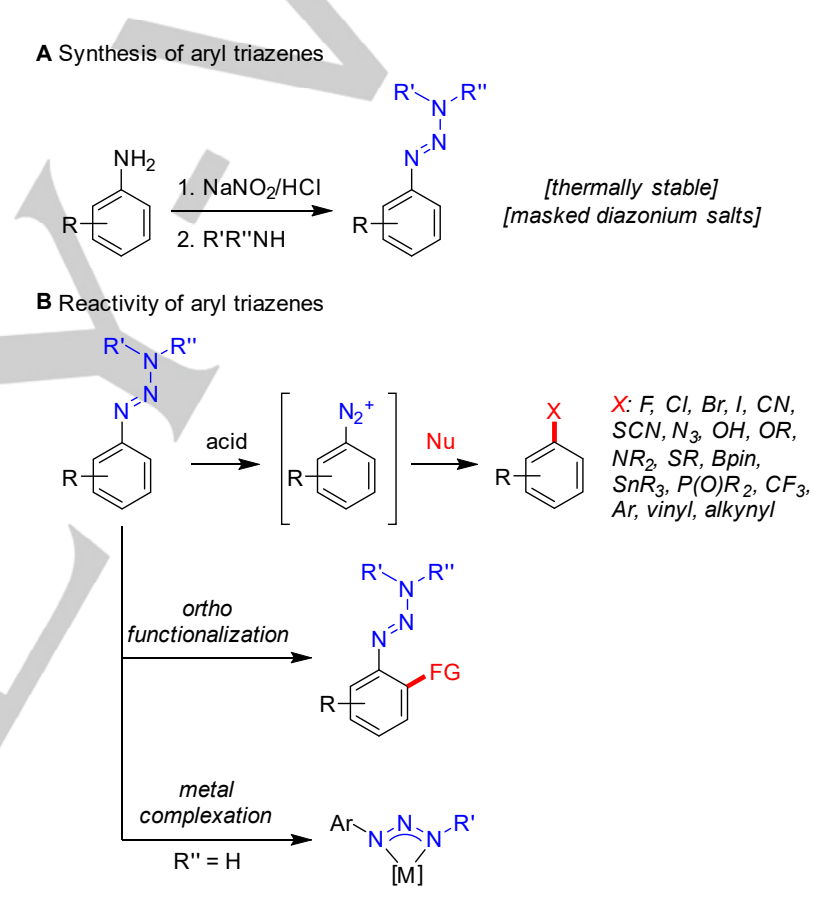

Scheme 2. Synthesis and reactivity of aryl triazenes.

For applications, 1-aryl-3,3-dialkyltriazenes are particularly attractive. These compounds display high stability towards bases and reducing agents. ${ }^{[2]}$ Upon addition of Brønsted or Lewis acids, however, the triazene group can be replaced by a broad range of other functionalities (Scheme 2B). ${ }^{[1]}$ The substitution reactions proceed by acid-induced rupture of the N2-N3 bond. ${ }^{[3]}$ The resulting diazonium ion can then undergo subsequent transformations. In view of this reactivity, aryl triazenes are often referred to as 'masked diazonium salts'. ${ }^{[1,4]}$ The facile conversion of Ar- $\mathrm{N}_{3} \mathrm{RR}$ ' into Ar-X compounds is a key characteristic of aryl triazenes, which has enabled different applications. For example, substitution reactions were employed in the context of natural product synthesis, ${ }^{[5]}$ and they are the basis for the use of polymersupported reagents with triazene linkers. ${ }^{[6,7]}$ The possibility to use 
aryl triazenes as a stable diazonium source ${ }^{[8]}$ has also been exploited in the context of materials chemistry. For example, aryl triazenes were used for the surface modification of silicon,,$^{[9]}$ carbon nanotubes, ${ }^{[10]}$ glassy carbon and gold electrodes. ${ }^{[11]}$

The triazene groups are Lewis bases, which can serve as directing groups in metal-mediated ortho $\mathrm{C}-\mathrm{H}$ or $\mathrm{C}-\mathrm{X}$ functionalization reactions (Scheme $2 \mathrm{~B}$ ). ${ }^{[1 \mathrm{c}, 5 \mathrm{c}-\mathrm{d}, 12]}$ The products can be further transformed into heterocycles, and polyaromatic hydrocarbons. A superior metal coordination is observed for anionic, difunctionalized triazenes, which have been used extensively as ligands for transition and main group metals (Scheme 2B). ${ }^{[13]}$

Apart from synthetic applications, triazenes have been investigated extensively in the context of medicinal chemistry. ${ }^{[14]}$ Two triazene-based drugs, dacarbazine and temozolomide (Scheme 3), are employed in the clinic as anticancer agents. Dacarbazine is used for the treatment of melanoma and Hodgkin's lymphoma, whereas temozolomide is used to treat brain tumors. ${ }^{[15]}$ In the body, both compounds liberate the methyl diazonium ion, ${ }^{[14,16]}$ which can alkylate guanine in DNA, ultimately leading to cell apoptosis.

A Triazene-based anticancer drugs

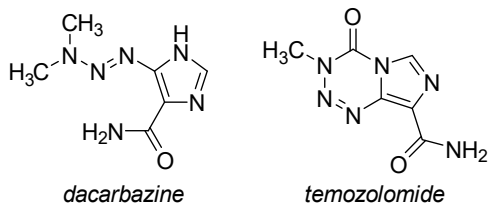

B Mechanism of action

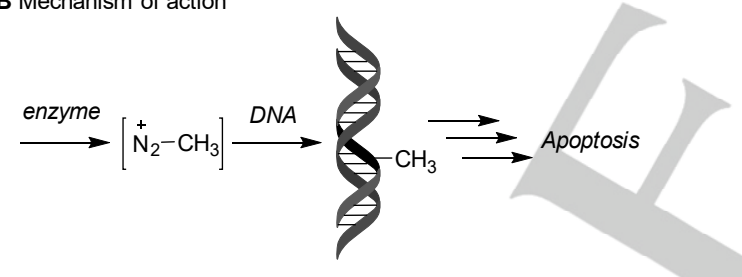

Scheme 3. Triazenes as anticancer drugs.

\section{Alkynyl Triazenes}

Given the importance of aryl triazenes, it may seem surprising that other unsaturated triazenes had hardly been studied until recently. For alkynyl triazenes, there is a simple explanation: the standard procedures to make aryl triazenes cannot be used for the synthesis of alkynyl triazenes, either because the required starting materials are unstable (e.g. alkynyl azides), or because other products are obtained. ${ }^{[17]}$ In 2015 , our group discovered a method for the preparation of alkynyl triazenes using an unusual reagent: gaseous nitrous oxide $\left(\mathrm{N}_{2} \mathrm{O}\right) \cdot{ }^{[18,19]}$ When $\mathrm{N}_{2} \mathrm{O}(1 \mathrm{~atm})$ is combined with lithium $\mathrm{N}, \mathrm{N}$-dialkylamides in THF, aminodiazotates $^{[18 \mathrm{~b}]}$ are formed. Upon addition of alkynyl Grignard reagents and gentle heating, alkynyl triazenes are then obtained in good yields (Scheme 4A).

It is worth noting that alkynyl triazenes are easy to work with: they can be purified by chromatography on triethylaminedeactivated silica, they are not particularly sensitive to air or moisture, and their thermal stability is good (e.g. toluene solutions

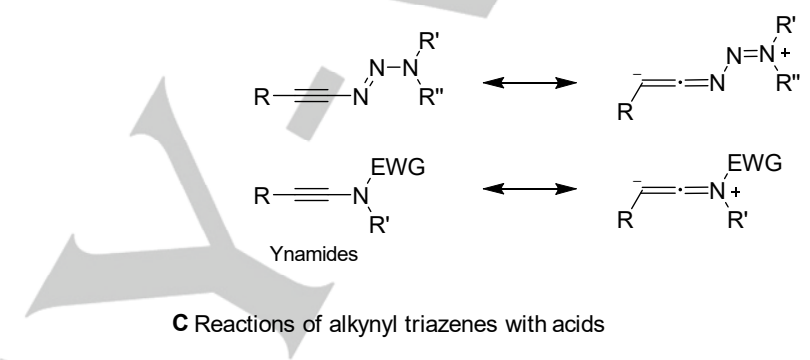

of some alkynyl triazenes can be heated to $100^{\circ} \mathrm{C}$ without noticeable decomposition).

The dialkyltriazenyl group is electron-donating, leading to a polarization of the triple bond. This polarization is reflected by a possible resonance structure, which shows a negative charge at the beta carbon atom and a positive charge at N3 (Scheme 4B). A similar zwitterionic resonance structure has been discussed for ynamides, which represent highly valuable reagents in synthetic organic chemistry.[20] Consequently, the question arose of whether alkynyl triazenes would display an ynamide-like reactivity.

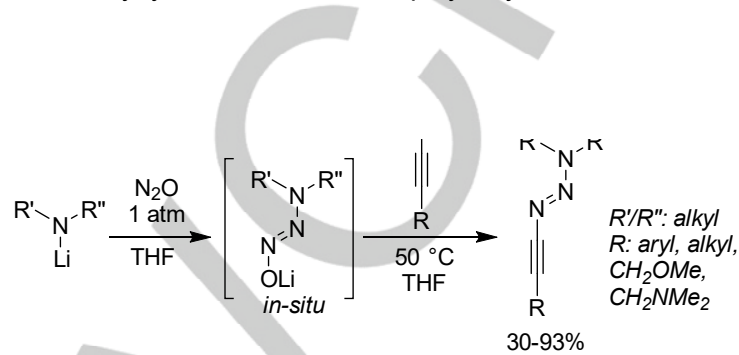

B Resonance structures of alkynyl triazenes and ynamides

Reactions of alkynyl triazenes with acids

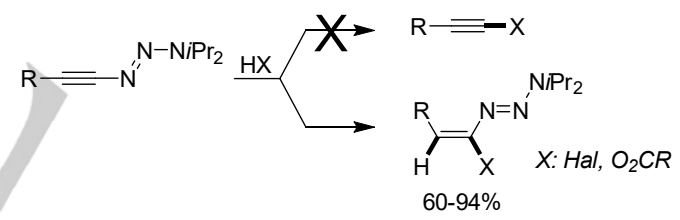

Scheme 4. Synthesis and reactivity of alkynyl triazenes. THF: tetrahydrofuran, EWG: electron-withdrawing group.

First evidence for a functional analogy between alkynyl triazenes and ynamides was observed in reactions with acids. As described in the Introduction, triazenes tend to be acid-sensitive. However, reactions of alkynyl triazenes with different Brønsted acids did not result in cleavage of the triazene group. Instead, a clean cis-addition to the triple bond was observed (Scheme $4 C$ ). ${ }^{[21]}$ The regioselectivity of the addition reflects the polarization of the triple bond, with protonation occurring at the nucleophilic beta carbon atom

Subsequent studies showed that alkynyl triazenes are able to undergo [2+2] cycloadditions with ketenes (generated in situ from acyl chlorides), [3+2] cycloadditions with a donor-acceptor cyclopropane, and reactions with tetracyanoethylene (Scheme 5). ${ }^{[21]}$ Similar transformations had been reported for ynamides. ${ }^{[22]}$ The results therefore corroborated the notion that alkynyl triazenes are activated alkynes with an ynamides-like reactivity. It is worth pointing out that the reactions shown in Scheme 5 all produce vinyl triazenes, the chemistry of which will be discussed in more detail in the next section of this review. 


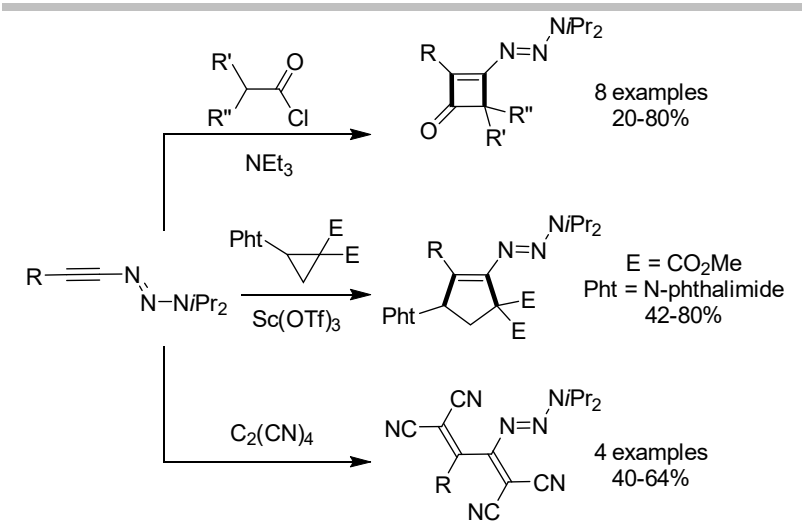

Scheme 5. Reactions of alkynyl triazenes with ketenes (generated in situ), with a donor-acceptor-substituted cyclopropane, and with tetracyanoethylene.

The ability to add HX selectively to the triple bond of alkynyl triazenes was further demonstrated by acetic acid-mediated addition reactions of $\mathrm{H}_{2} \mathrm{O}$ (Scheme $6 \mathrm{~A}$ ). ${ }^{[23]}$ This transformation leads to the formation 1-acyl triazenes, which had not been reported before. Acyl triazenes were also obtained by goldcatalyzed reactions with pyridine-N-oxide, or by oxyhalogenation with N-bromo- or N-chlorosuccinamide (NCS and NBS). ${ }^{[23]}$ The acyl group at $\mathrm{N} 1$ position has a strong influence on the physical and chemical properties of the triazenes. Crystallographic analyses show extremely short N2-N3 bond lengths, and the energy barrier for rotation around this bond is much higher than what has been reported for other triazenes. Acyl triazenes are thermally robust compounds, and bases or oxidants are well tolerated. Under acidic conditions, acyl triazenes act as acylating agents (Scheme 6B).

A Synthesis of acyl triazenes

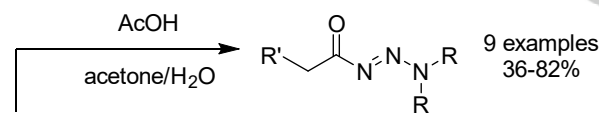

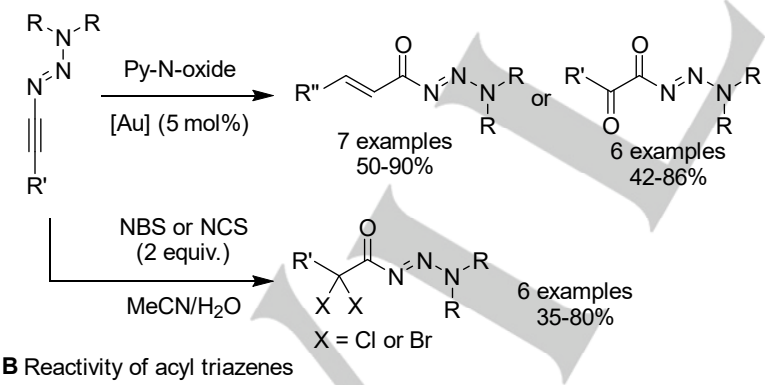

B Reactivity of acyl triazenes

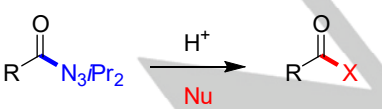

$$
\begin{aligned}
& \text { Nu: } \mathrm{D}_{2} \mathrm{O}, \mathrm{CD}_{3} \mathrm{OD}, \mathrm{PhNH}_{2} \text { PhOMe }
\end{aligned}
$$

Scheme 6. Synthesis and reactivity of acyl triazenes.

Alkynyl triazenes with propargyl groups can be isomerized with KOtBu into allenyl triazenes (Scheme 7). ${ }^{[24]}$ The latter display only moderate thermal stability, and this fact might limit synthetic applications. However, depending on the substitution pattern, they can be hydrolyzed or isomerized to give more stable vinyl triazenes. The Lewis acid $\mathrm{ZnCl}_{2}$ induces a rearrangement into $\mathrm{N}$-aminopyrazoles.

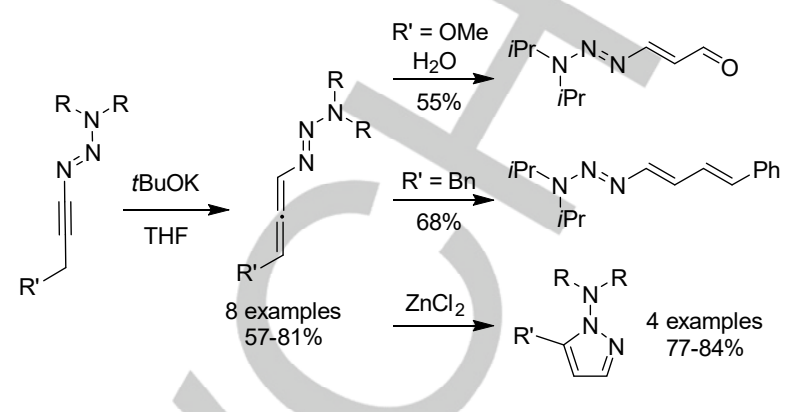

Scheme 7. Synthesis of allenyl triazenes.

In the presence of gold catalysts, propargyl-based alkynyl triazenes can undergo coupling reactions with imines to give 1,3-diaminopyrazole derivatives in moderate to good yields (Scheme 8). ${ }^{[25]}$ As in the case of the $\mathrm{ZnCl}_{2}$-induced rearrangement of allenyl triazenes (Scheme 7), the $\mathrm{N}_{3} R_{2}$ group is involved in the transformation. This finding shows that alkynyl triazenes can undergo transformations, which are distinct from those of other activated alkynes such as ynamides.

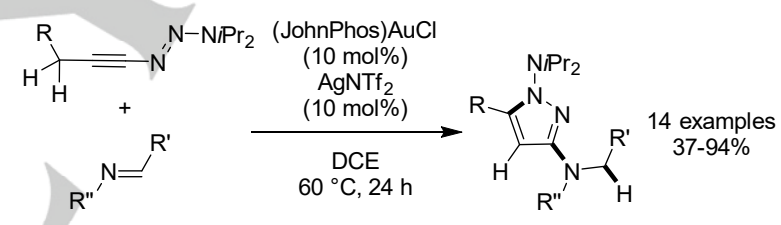

Scheme 8. Synthesis of $\mathrm{N}$-aminopyrazoles from alkynyl triazenes. DCE: dichloroethane.

Aryl triazenes can be obtained from the corresponding aromatic amines by diazotization and addition of dialkylamines (Scheme 1A). However, the required aniline derivatives can be expensive or difficult to access. Ru-catalyzed [2+2+2] cyclotrimerization reactions between tethered diynes and alkynyl triazenes can be used as an alternative way to build densely substituted aryl triazenes (Scheme 9A). ${ }^{[26]}$ The reaction is carried out with $\left[\mathrm{Cp}^{*} \mathrm{RuCl}_{2}\right]_{2}\left(\mathrm{Cp}^{*}=\right.$ pentamethylcyclopentadienyl $)$ as catalyst precursor, and it gives the cyclization products with high regioselectivity.

A similar methodology can be used to access pyridyl triazenes (Scheme 9A). Two possibilities have been explored: a) reactions of tethered alkynyl nitriles with alkynyl triazenes, and b) reactions of diynyl triazenes with nitriles. The former cyclization is best performed in 1,4-dioxane with $\left[\mathrm{Cp}^{*} \mathrm{Ru}(\mathrm{MeCN})_{3}\right] \mathrm{PF}_{6}$ and a halide additive, whereas the latter can be achieved with $\left[\mathrm{Cp}^{*} \mathrm{RuCl}_{2}\right]_{2}$. The regioselectivity of these reactions is also very good.

Prior to these studies, the reactivity profile of pyridyl triazenes had not been explored in detail. It turned out that the triazene group can be converted into a variety of important functional groups, including fluoride (Scheme 9B). ${ }^{[26]}$ These findings 
underline the potential of aromatic triazenes in divergent organic synthesis.

In the context of these investigations, the coordination chemistry of $\mathrm{Cp}^{*} \mathrm{RuCl}$ and alkynyl triazenes was studied. Crystallographically characterized adducts include a $\mathrm{Cp}{ }^{*} \mathrm{RuCl}\left(\eta^{2}-\right.$ alkyne) complex and a $\mathrm{Cp}^{*} \mathrm{RuCl}\left(\eta^{2}\right.$-cyclobutadiene $)$ complex. The latter is catalytically inactive, and its formation might be involved in catalyst deactivation. ${ }^{[26]}$

$$
\begin{aligned}
& \text { A Synthesis of aryl and pyridyl triazenes (Ru catalysis) }
\end{aligned}
$$

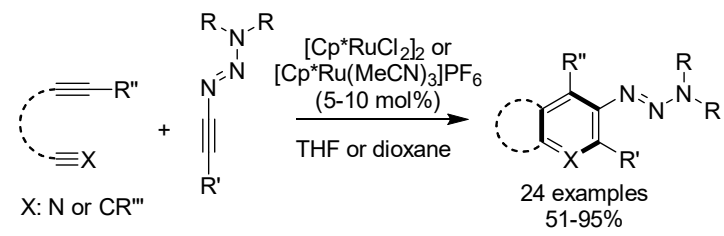

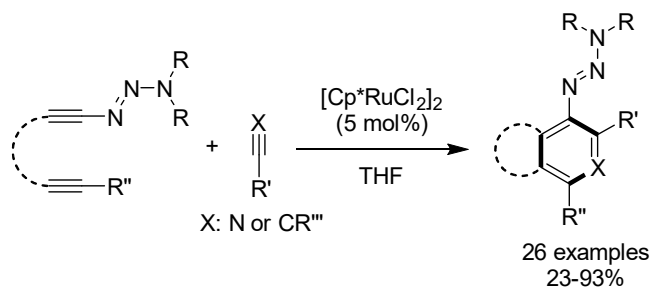

B Substitution of the triazene group

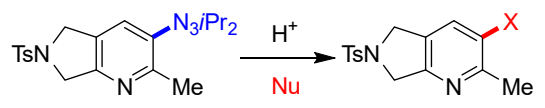

$$
X: F, I, N_{3}, O M e, N H A c, A r \text {, vinyl }
$$

Scheme 9. Synthesis of densely substituted arenes and pyridines by Rucatalyzed $[2+2+2]$ cycloadditions.

Annulation reactions involving $\mathrm{C}-\mathrm{H}$ activation represent another possibility to incorporate alkynes into arenes. ${ }^{[27]}$ In order to access polycyclic heteroaryl triazenes, alkynyl triazenes were coupled to phenyl-substituted imidazoles, indoles, and sydnones by $\mathrm{Cp}^{*} \mathrm{Rh}$-catalyzed double $\mathrm{C}-\mathrm{H}$ or $\mathrm{C}-\mathrm{H} / \mathrm{N}-\mathrm{H}$ activation reactions (Scheme 10A). ${ }^{[28]}$

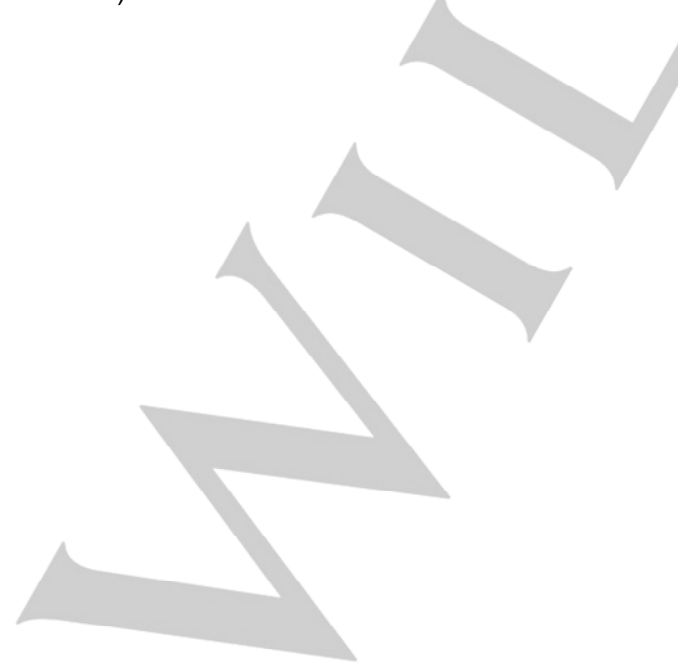

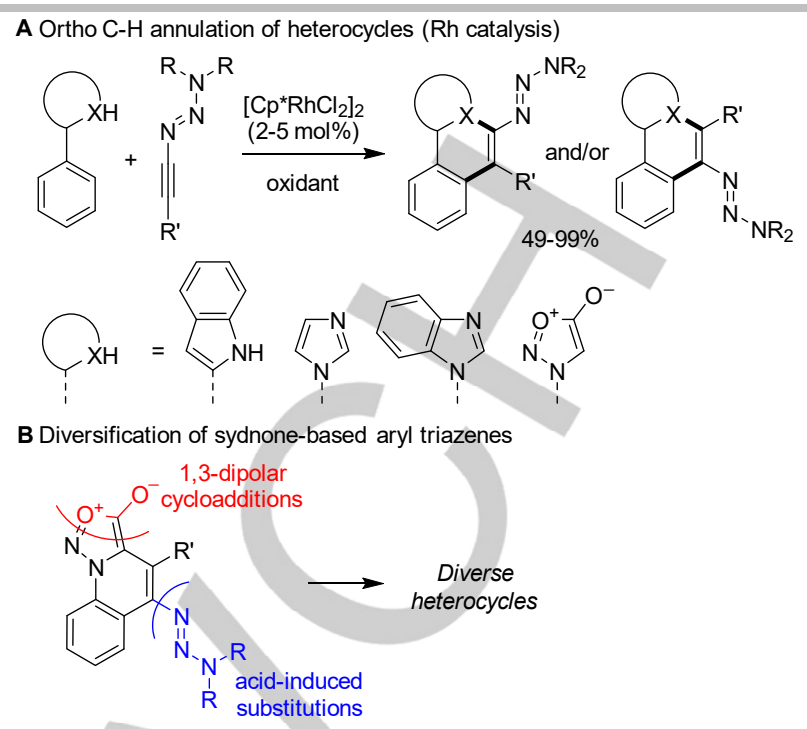

Scheme 10. Oxidative $\mathrm{C}-\mathrm{H}$ annulation reactions with alkynyl triazenes.

For reactions with phenyl-substituted imidazoles and indoles, the yields (49-82\%) were affected to some extend by degradation of the acid-sensitive alkynyl triazenes. Better yields were obtained for reactions with phenylsydnone, which could be performed under milder conditions (RT). The resulting coupling products were used for subsequent orthogonal transformations (Scheme 10B). ${ }^{[28]}$ The sydnone moiety allowed for postfunctionalization via 1,3-dipolar cycloadditions, whereas the triazene group could be substituted by a range of functional groups (e.g. azide, bromide, or iodide).

Besides oxidative $\mathrm{C}-\mathrm{H}$ activation reactions, alkynyl triazenes have been used as substrates in redox-neutral annulation reactions with $\mathrm{N}$-(pivaloyloxy)acrylamides. ${ }^{[29]}$ The $\mathrm{Cp}^{*} \mathrm{Rh}^{11 !}$ catalyzed reactions were found to proceed with Lossen rearrangement to give 4-triazenyl-2-pyridones with high selectivity. These triazenes can be converted in-situ with HF-pyridine into 4-fluoro-2-pyridones. The results highlight the utility of alkynyl triazenes as surrogates of unstable fluoroalkynes.

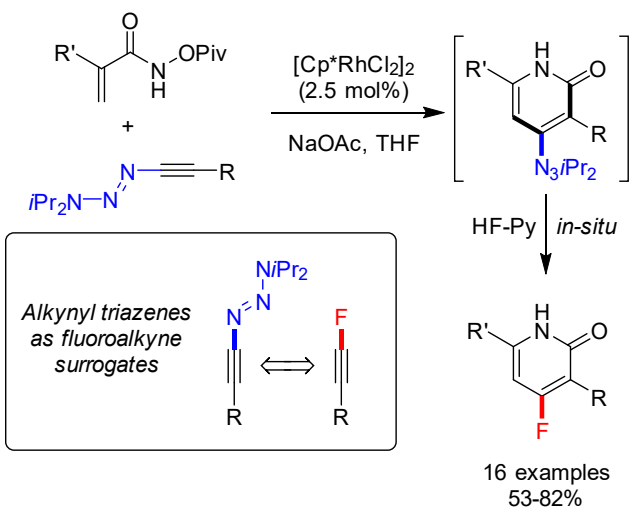

Scheme 11. Synthesis of fluoropyridones via Rh-catalyzed C-H annulation. 


\section{WILEY-VCH}

Ir-catalyzed [3+2] cycloaddition reactions of alkynyl triazenes with azides were used to prepare triazenyl triazoles under mild conditions in high yields (Scheme 12A). ${ }^{[30]}$ The products can be converted into 5-amino triazoles by reduction with Raney-Ni (Scheme 12B). Further functionalization was achieved by diazotization and nucleophilic substitution.

A Synthesis of triazolyl triazenes (Ir catalysis)

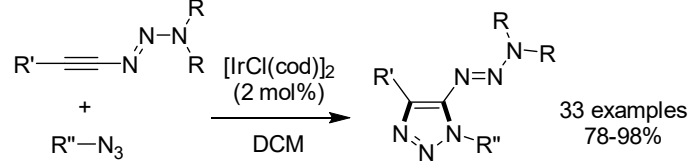

B Reduction to aminotriazoles

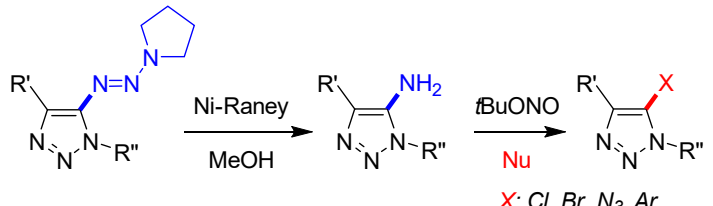

Scheme 12. Ir-catalyzed [3+2] cycloaddition reactions with azides. DCM: dichloromethane, cod: 1,5-cyclooctadiene.

\section{Vinyl Triazenes}

The synthesis of triazenes from azides and Grignard reagents was first described in 1903 by Dimroth. ${ }^{[31]} \mathrm{He}$ found that MeMgl and phenylazide forms an adduct, which can be hydrolyzed to give the disubstituted triazene $\mathrm{PhN}_{3} \mathrm{HMe}$. More than 60 years later, a similar route was used by Miller and Jones to make vinyl triazenes. ${ }^{[32]}$ They have combined triarylvinyl Grignard reagents with aryl azides to make triazenes of the general formula $\mathrm{Ar}_{2} \mathrm{C}=\mathrm{CAr}\left(\mathrm{N}_{3} \mathrm{HAr}\right)$ (Scheme 13A). Soon after, structurally related vinyl triazenes were reported by Akimova and co-workers. ${ }^{[33]}$ However, it was noted by Miller that the scope of this methodology is limited. ${ }^{[34]}$

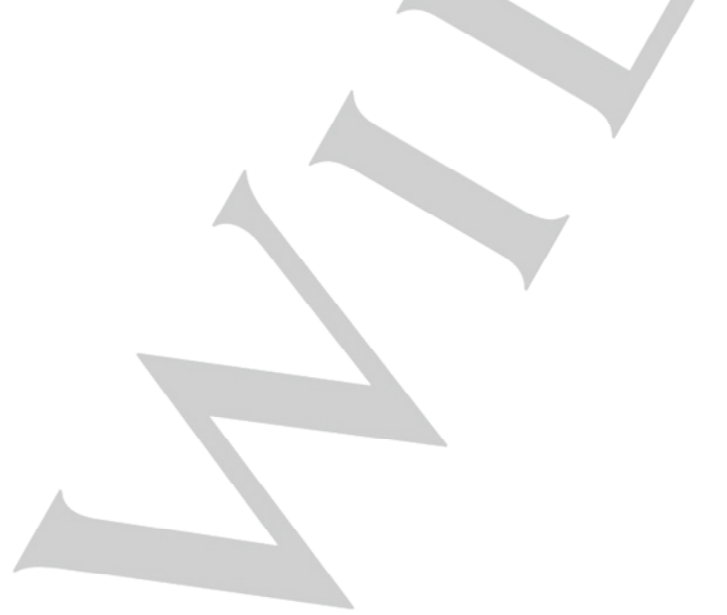
A Vinyl Grignard reagents and aryl azides

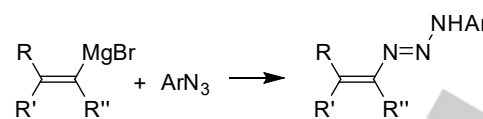
Jones et al. (1967)
$\mathrm{R}^{\prime} \mathrm{R}^{\prime \prime}+\mathrm{ArN}_{3} \longrightarrow \mathrm{R}^{\prime} \quad$ Akimova et al. (1968)

B Aryl azide and sulfonium ylide

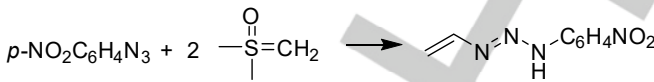

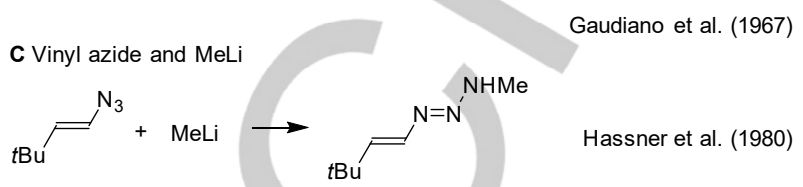

D Base-induced elimination

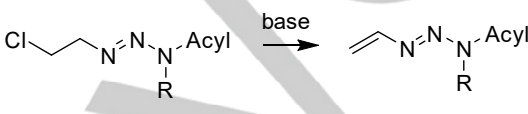

Smith et al. (1995)

E Vinyl Grignard reagents and amino diazotates

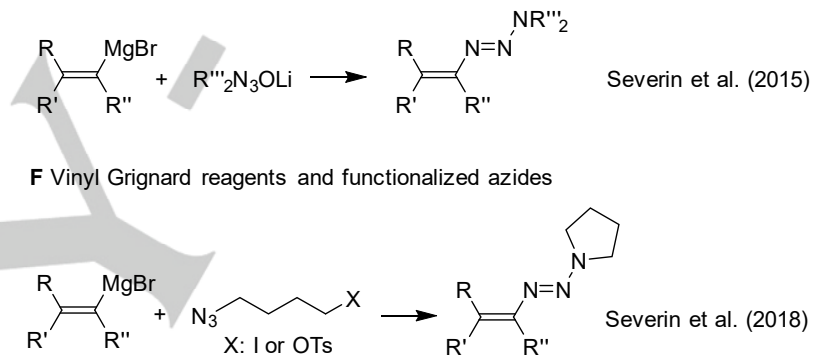

G Addition reactions to alkynyl triazenes

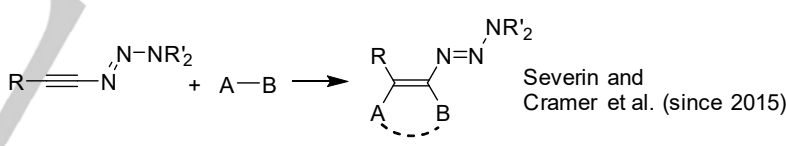

Scheme 13. Synthesis of vinyl triazenes.

The synthesis of a triazene with a simple ethenyl substituent was reported by Gaudiano et al.. ${ }^{[3]}$ The compound was prepared by reaction of a sulfoxonium ylide with $p$-nitrophenyl azide (Scheme 13B). The nitro group on the azide was found to be crucial for the success of the reaction, with other aromatic azides giving triazolines instead of triazenes.

Instead of coupling of metallated olefins with azides, it is possible to couple vinyl azides with organometallic reagents. This approach was used by Hassner and co-workers for the synthesis of triazenes such as $\mathrm{tBuC}=\mathrm{CH}\left(\mathrm{N}_{3} \mathrm{HMe}\right)$ (Scheme 13C). ${ }^{[36]}$

The base-induced conversion of 2-chloroethyl triazenes into vinyl triazenes was investigated by Smith and co-workers (Scheme 13D). ${ }^{[37]}$ The elimination reactions can be achieved with weak bases such as alkylamines. However, side products due to de-acylation were observed for some substrates.

The methods depicted in Scheme 13A-C all give disubstituted vinyl triazenes, which can exist in two tautomeric forms (RNH-N=N-R' and $\left.\mathrm{R}-\mathrm{N}=\mathrm{N}-\mathrm{NH}-\mathrm{R}^{\prime}\right)$. Triazene tautomers can display different reactivity, ${ }^{[1,38]}$ and it is therefore desirable to work with trisubstituted vinyl triazenes. One possibility is the 
postsynthetic alkylation or acylation of the $\mathrm{N}-\mathrm{H}$ group of disubstituted triazenes, ${ }^{[39]}$ but these reactions can give rise to product mixtures. We have explored synthetic routes, which directly provide trisubstituted vinyl triazenes.

As discussed in the previous section, the reaction of lithium dialkyl amides with nitrous oxide gives aminodiazotates. When mixed with vinyl Grignard reagents, vinyl triazenes are formed in good yields (Scheme 13E). ${ }^{[18]}$ Due to the presence of two alkyl groups, the triazenes display increased stability, allowing for a chromatographic purification on deactivated silica gel.

In 2018, we have reported a variant of the Grignard-azide route, which gives directly trisubstituted vinyl triazenes. The reactions are enabled by the azide reagents 1-azido-4iodobutane or 4-azidobutyl-4-methylbenzenesulfonate, which contain an alkylating part. ${ }^{[40]}$ Combined with vinyl Grignard reagents, vinyl triazenes with pyrrolidine group are obtained in a single step. The reaction works equally well with aryl Grignard reagents, but not with alkynyl magnesium compounds. For synthesizing alkynyl triazenes, the $\mathrm{N}_{2} \mathrm{O}$-based method described in Scheme 4A is the only option so far.

A key limitation of the reactions discussed above is the utilization of a strongly nucleophilic organometallic reagent (RMgX or RLi), which compromises the functional group compatibility. In order to prepare structurally and functionally complex vinyl triazenes, addition reactions to alkynyl triazenes are an interesting option (Scheme 13G). Some selected reactions were shown in the previous section (Scheme 5), and additional examples are given below. But first, we would like to discuss the general reactivity of vinyl triazenes.

Vinyl triazenes are susceptible to acid-induced cleavage reactions. In analogy to the general reactivity of aryl triazenes, it is assumed that the acid promotes a rupture of the N2-N3 bond, generating a vinyl diazonium ion (Scheme 14). The latter is prone to lose dinitrogen ${ }^{[41]}$ to give a vinyl cation, which can then engage in reactions with nucleophiles.

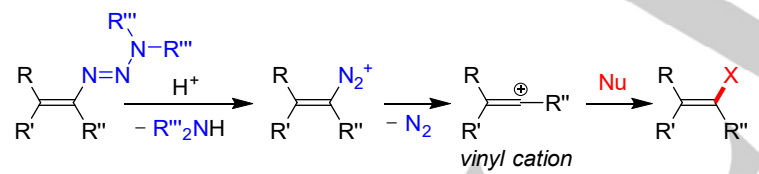

Scheme 14. Reactivity of vinyl triazenes.

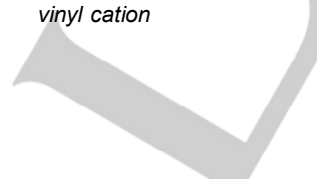

First experimental evidence that vinyl triazenes can serve as precursors for vinyl cations was reported by Miller and Jones. ${ }^{[32]}$ They have studied reactions of $\operatorname{Ar}_{2} \mathrm{C}=\mathrm{CAr}\left(\mathrm{N}_{3} \mathrm{HAr}\right)$ triazenes with oxo acids, and they observed liberation of dinitrogen and replacement of the $\mathrm{N}_{3} \mathrm{HAr}$ group with oxo acid anions. The transformations were accompanied by 1,2-aryl shifts, which are characteristic for reactions involving vinyl cations. Subsequent studies by Lee et al. with ${ }^{14} \mathrm{C}$-labelled triazenes corroborated the findings. ${ }^{[42]}$

Vinyl cations are well suited for electrophilic vinylation reactions, and the generation of these highly reactive intermediates has received considerable interest. ${ }^{[43]}$ Vinyl cations are typically produced by heterolytic $\mathrm{C}-\mathrm{X}$ bond cleavage ${ }^{[44]}$ or by reaction of cationic electrophiles with alkynes. ${ }^{[45]}$ Despite the promising pioneering studies by Jones, ${ }^{[32]}$ the utilization of vinyl triazenes as vinyl cation precursors has been neglected until recently. Following the discovery of new protocols for the synthesis of vinyl triazenes (Scheme 13E-G), different substitution reactions have now been studied. These investigations have shown that vinyl triazenes are versatile and convenient surrogates for vinyl cations.

First evidence that the triazene group can be replaced by functions other than oxo acids was provided in 2017. ${ }^{[46]}$ In collaboration with the group of Cramer, we have investigated [2+2] cycloaddition reactions between alkynyl triazenes and bicyclic alkenes in the presence of a Ru catalyst with a chiral cyclopentadienyl ligand. The reactions give a broad range of cyclobutenyl triazenes in good yields and with high enantioselectivity (Scheme 15A).

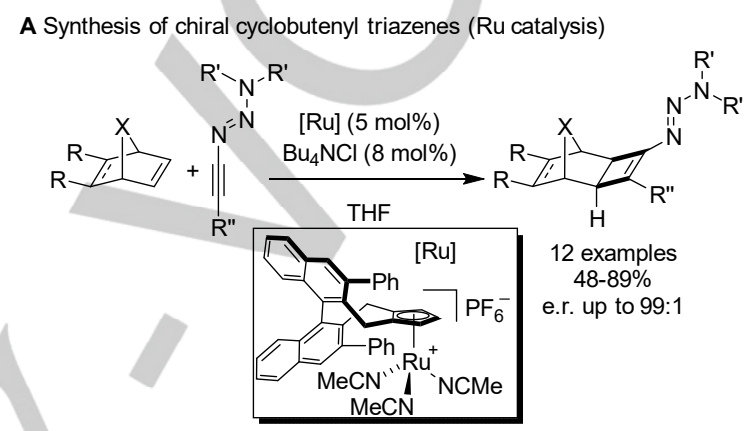

B Synthesis of chiral polycycles
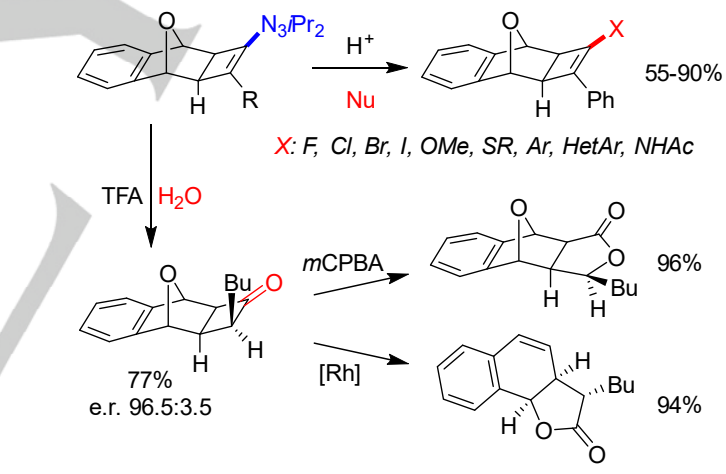

Scheme 15. Synthesis and reactivity of cyclobutenyl triazenes. mCPBA: metachloroperoxybenzoic acid.

In the presence of Brønsted acids, the triazene functionality can be replaced by a variety of groups including halides, alkoxides, sulfides, arenes, heteroarenes, and amides, providing access to a pool of chiral polycyclic compounds (Scheme 15B). In most cases, the substitution reactions occur without racemization, but for weak nucleophiles and for triazenes featuring a phenyl substituent adjacent to the triazene function, some erosion of the enantioselectivity was observed. These findings are in line with the proposed vinyl cation intermediate. Triazene cleavage in the presence of water gives a cyclobutanone, which can be further transformed into lactones.

Cyclobutenyl cations are particularly stable vinyl cations. ${ }^{[47]}$ In order to demonstrate that substitution reactions are also possible with 'normal', non-cyclic vinyl triazenes, cleavage reactions with $\mathrm{Me}_{2} \mathrm{C}=\mathrm{CPh}\left(\mathrm{N}_{3} \mathrm{C}_{4} \mathrm{H}_{8}\right)$ were investigated (Scheme 16). ${ }^{[40]}$ Under 
acidic conditions, it was possible to introduce butylsulfides, amides, fluoride, methoxide, and a phosphonate. The MichaelisArbuzov-type reaction with $\mathrm{P}(\mathrm{OEt})_{3}$ represents the first metal-free synthesis of a tetrasubstituted alkenyl phosphonate.

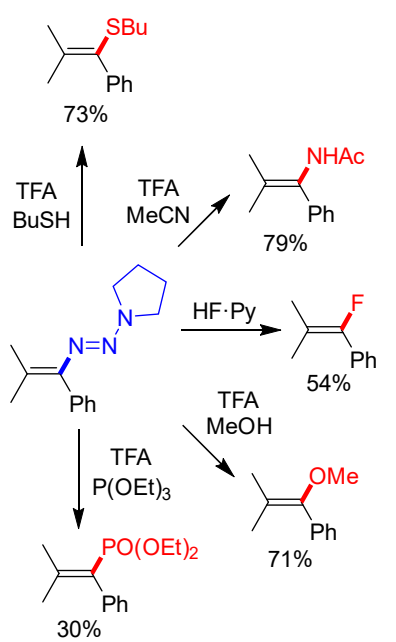

Scheme 16. Acid-mediated cleavage reactions of a vinyl triazene. TFA: trifluoroacetic acid, Py: pyridine.

As illustrated below, vinyl triazenes are also accessible by Pdcatalyzed addition reactions to alkynyl triazenes (Scheme 17). ${ }^{[48]}$ Hydrogenation over Lindlar's catalyst leads to the formation of $Z$ vinyl triazenes in high yields. Vinyl triazenes with aryl groups at $\mathrm{C}_{\alpha}$ can be prepared by hydroarylation reactions with arylboronic acids. An advantage of this reactions is the possibility to prepare vinyl triazenes with functional groups such as amines, aldehydes, and esters, which could be used for further synthetic transformations. The haloallylation of alkynyl triazenes gives tetrasubstituted vinyl triazenes. The products can serve as substrates in Suzuki coupling reactions, providing differentially substituted vinyl triazenes.

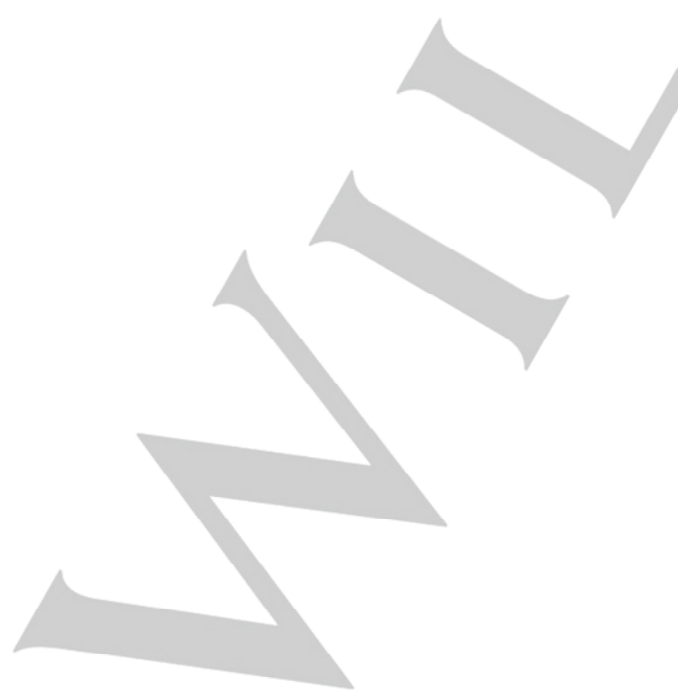

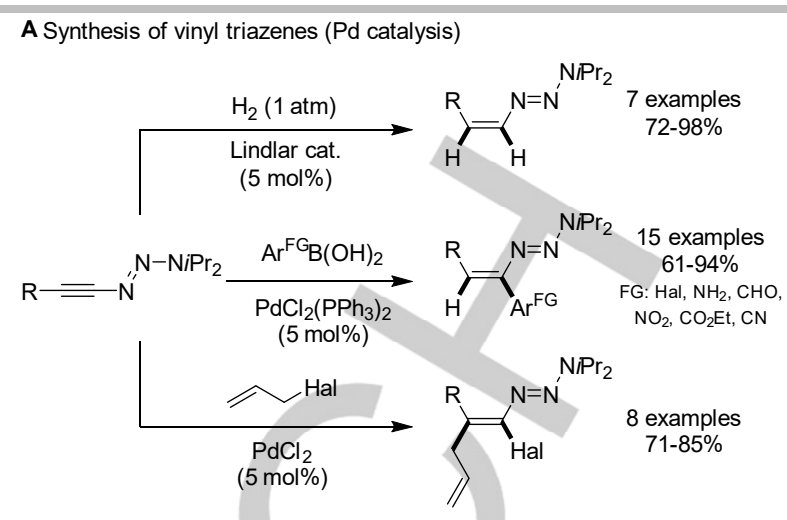

B Synthesis of differentially-substituted vinyl triazene

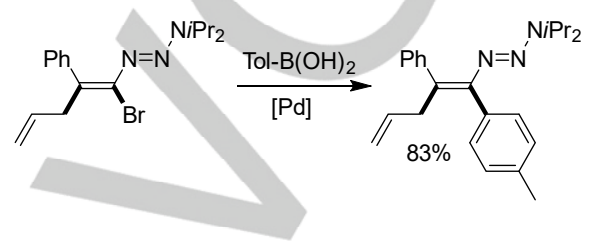

Scheme 17. Synthesis of vinyl triazenes by Pd-catalyzed addition reactions.

Aryl boronic acids with functional groups in ortho position can undergo $\mathrm{Rh}^{\prime}$-catalyzed annulation reactions with alkynyl triazenes to give indenyl triazenes (Scheme 18). ${ }^{[49]}$ The regioselectivity of these reactions is mostly high, and strongly dependent on the substituent at the triple bond. The triazene group in the products can be cleaved by addition of acids. However, these reactions do not result in direct substitution of the triazene by nucleophiles, as observed for other vinyl triazenes. Instead, substrate-specific rearrangements are observed.

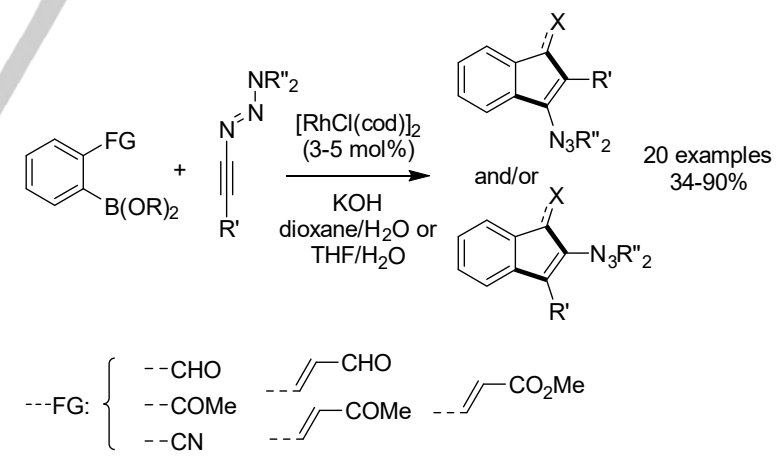

Scheme 18. Synthesis of indenyl triazenes.

Compounds which become luminescent upon aggregation have found numerous applications in analytical chemistry, imaging, materials sciences, and biology. ${ }^{[50]}$ Tetraarylethenes are among the most popular aggregation-induced emission (AIE) luminogens. ${ }^{[50 a]}$ Recently, we have described a simple, fast, and versatile protocol for the preparation of tetraarylethenes. ${ }^{[51]}$ The new method relies on the acid-induced coupling of vinyl triazenes with aromatic compounds (Scheme 19). The key reagent is a disubstituted triphenylethenyl triazene, $\mathrm{Ph}_{2} \mathrm{C}=\mathrm{CPh}\left(\mathrm{N}_{3} \mathrm{HPh}\right)$, which was first described by Miller and Jones in $1967 .{ }^{[32]}$ As depicted in 
Scheme 13A, it can be obtained from triphenylethenyl magnesium bromide with phenyl azide, and it can easily be made on gramscale. With this reagent, one can graft triarylethenyl groups on a variety of aromatic compounds, including heterocycles, supramolecular hosts, biologically relevant molecules, and commercial polymers. The possibility to use arenes as coupling partners is a key advantage of this method, as non-functionalized aromatic compounds can be converted in a single step into solid state emitters.

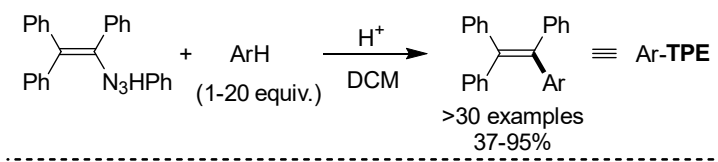

Aggregation-Induced Emission (AIE) Luminogens<smiles></smiles>

benzenes

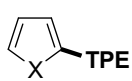

heteroarenes<smiles>CC(C)c1ccc2c(c1)-c1ccccc1C2</smiles>

$\mathrm{PAHs}$

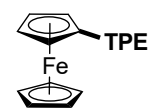

ferrocene<smiles>CC(C)c1ccc2c(c1)OCCOCCOCCOCCO2</smiles>

benzocrown ethers

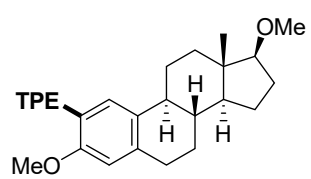

bioactive molecules<smiles>CC(c1cccc(C(C)(F)F)c1)C(C)C(F)(F)F</smiles>

polystyrene<smiles>CCc1cc(Cl)c(CC)c(C(C)C)c1</smiles>

parylene C

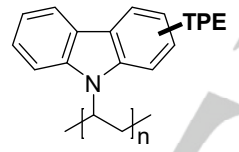

polyvinylcarbazole

Scheme 19. Synthesis of tetraarylethenes by $\mathrm{C}-\mathrm{H}$ vinylation of arenes. The products can display aggregation-induced emission (AIE).

A Synthesis of triazene-activated donor-acceptor cyclopropanes

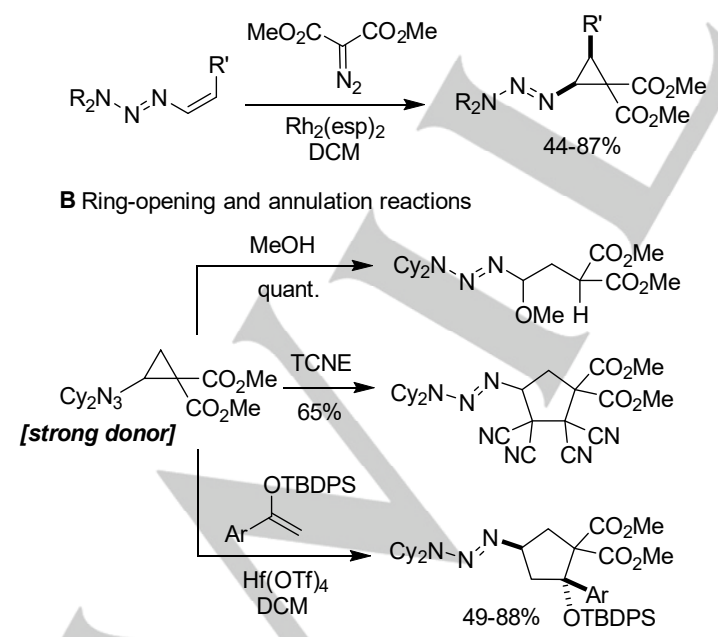

Scheme 20. Synthesis and reactivity of triazene-activated donor-acceptor cyclopropanes. $\quad \mathrm{Rh}_{2}(\mathrm{esp})_{2}: \quad \operatorname{Bis}\left[\operatorname{rhodium}\left(\alpha, \alpha, \alpha^{\prime}, \alpha^{\prime}\right.\right.$-tetramethyl-1,3benzenedipropionic acid)]
Donor-acceptor (D-A) cyclopropanes with triazene groups can be obtained by $\mathrm{Rh}$-catalyzed reaction of vinyl triazenes with dimethyl diazomalonate (Scheme 20A). ${ }^{[52]}$ The $\mathrm{N}_{3} \mathrm{R}_{2}$ group provides a very strong activation of the cyclopropane ring, allowing for catalyst-free reactions with methanol and TCNE (Scheme 20B). This type of reactivity is unusual, and 'standard' D-A cyclopropanes with $\mathrm{N}$-phthalimide or 4-methoxyphenyl do not react under these conditions. The triazenyl cyclopropanes can undergo Lewis acid-catalyzed cycloaddition reactions with silyl enol ethers, which give highly-functionalized cyclopentanes.

\section{Conclusions and Outlook}

In this Minireview, we have summarized the chemistry of vinyl- and alkynyl triazenes. Research on alkynyl triazenes was enabled by a serendipitous discovery. In 2015 , we found that alkynyl triazenes are formed in reactions of dialkylamides, nitrous oxide, and alkynyl Grignard reagents. ${ }^{[18]}$ The $\mathrm{N}_{2} \mathrm{O}$-mediated coupling between amides and alkynyl Grignards can be performed conveniently in one-pot under mild conditions, and it allows preparing a range of alkynyl triazenes in good yields. The electron-donating nature of the triazene group leads to an activation of the triple bond, thereby facilitating regioselective addition reactions. Alkynyl triazenes can be used as substrates for transition metal-catalyzed reactions, as evidenced by addition, cyclization, and annulation reactions with $\mathrm{Pd}, \mathrm{Ru}, \mathrm{Rh}, \mathrm{Ir}$ and $\mathrm{Au}$ catalysts. Similar reactions can be performed with other alkynes, but there is an advantage of using alkynyl triazenes: the triazene function in the products can be substituted under acidic conditions with numerous other groups. Notably, it is often possible to replace the triazene function by fluoride. Alkynyl triazenes can thus be used as surrogates for unstable fluoroalkynes.

Whereas alkynyl triazenes were not known before 2015, the chemistry of vinyl triazenes dates back to $1967 .{ }^{[32,35]}$ However, synthetic access was limited, and only few studies about vinyl triazenes were published until recently. In the meantime, the situation has changed, and vinyl triazenes can now be prepared via different routes. Already in 1967, it was proposed that vinyl triazenes can serve as precursors for vinyl cations. ${ }^{[32]}$ This proposition was substantiated by recent studies, which have shown that acidic conditions unleash a vinyl cation-like reactivity. The possibility to use vinyl triazenes as stable and easy-to-handle precursors for vinyl cations represents an interesting opportunity for synthetic applications. For example, we have recently shown that tetrarylethene AIE luminogens can be prepared by $\mathrm{C}-\mathrm{H}$ vinylation of plain aromatic compounds with triazenes.

The studies published so far are evidence that vinyl- and alkynyl triazenes are highly interesting compounds with a unique reactivity. But there are other aspects, which deserve attention. For example, the biological activity of vinyl- and alkynyl triazenes is largely unknown. So far, only few vinyl- and alkynyl triazenes were tested for their anti-cancer activity. ${ }^{[18]}$ In view of the interesting pharmacology of the related aryl triazenes, more extensive biological tests seem worthwhile.

With unsaturated triazenes showing interesting chemistry, the question arises: what about saturated, alkyl triazenes? In fact, triazenes containing exclusively alkyl substituents are known for many years. ${ }^{[1]}$ They can be prepared by reaction of alkyl azides with lithium- or magnesium organic reagents. ${ }^{[39 a-c]}$ Past studies had focused on triazenes with simple substituents (e.g. methyl, 
ethyl, butyl, or benzyl). The recent study about triazene-activated cyclopropanes $^{[52]}$ demonstrates that it is possible to prepare structurally and functionally complex trialkyl triazenes from vinyl triazenes. At the moment, the reactivity of such compounds is largely unknown.

Finally, we would like to propose that it is worth investing the new triazenes in the context of radical chemistry. For some reactions of aryl triazenes, cleavage reactions of the $\mathrm{N}_{3} R_{2}$ group were suggested to give aryl radicals intermediates. ${ }^{[5,53]}$ These suggestions are in line with the fact that aryl diazonium salts (the primary decomposition products of aryl triazenes) are known precursors for aryl radicals. ${ }^{[54]}$ In analogy, it might be possible to generate reactive vinyl (or alkyl) radicals if cleavage reactions of vinyl (or alkyl) triazenes are performed in the presence of potential electron donors. Reactions of this type would further enlarge the potential of the new triazenes in synthetic chemistry.

\section{Acknowledgements}

The work was supported by the Swiss National Science Foundation. We thank Carl Thomas Bormann, Iris Landman, JinFay Tan, and Nicolai Cramer for valuable suggestions.

Keywords: triazenes $\cdot$ alkynes $\cdot$ catalysis $\bullet$ vinyl cation $•$ diazonium ion

[1] For reviews, see: a) W. Dong, Z. Chen, J. Xu, M. Miao, H. Ren, Synlett 2016, 27, 1318-1334; b) Y. Zhang, D. Cao, W. Liu, H. Hu, X. Zhang, C. Liu, Curr. Org. Chem. 2015, 19, 151-178; c) H. Sun, Y. Huang, Synlett 2015, 26, 2751-2762; d) D. K. Kölmel, N. Jung, S. Bräse, Aust. J. Chem. 2014, 67, 328-336; e) S. Bräse, T. Muller, Aryltriazenes, Aryltetrazenes and Related Compounds in Science of Synthesis, Georg Thieme, Stuttgart, 2007, 1845-1872; f) D. B. Kimball, M. M. Haley, Angew. Chem. Int. Ed. 2002, 41, 3338-3351; g) H. Zollinger, Diazo Chemistry I, Wiley VCH, 1994, 385-404; h) K. Vaughan, M. F. G. Stevens, Chem. Soc. Rev. 1978, 7, 377-397; i) T. W. Campbell, B. F. Day, Chem. Rev. 1951, 48, 299-317. For a recent review on related $\pi$-conjugated triazenes, see: j) S. Patil, A. Bugarin, Eur. J. Org. Chem. 2016, 860-870.

[2] a) R. Reingruber, S. Vanderheiden, A. Wagner, M. Nieger, T. Muller, M. Es-Sayed, S. Bräse, Eur. J. Org. Chem. 2008, 3314-3327; b) Very strong bases like $n \mathrm{BuLi}$ can react with 1-aryl-3,3-dialkyltriazenes: K. Nishiwaki, T. Ogawa, K. Matsuo, Angew. Chem. Int. Ed. 2002, 41, 484-486.

[3] I. R. Landman, A. A. Suleymanov, F. Fadaei-Tirani, R. Scopelliti, F. M. Chadwick, K. Severin, Dalton Trans. 2020, 49, 2317-2322. See also references cited therein.

[4] F.-X. Felpin, S. Sengupta, Chem. Soc. Rev. 2019, 48, 1150-1193.

[5] For examples, see: a) S. Ando, J. Burrows, K. Koide, Org. Lett. 2017, 19, 1116-1119; b) H. T. Dao, P. S. Baran, Angew. Chem. Int. Ed. 2014, 53, 14382-14386; c) K. C. Nicolaou, H. Li, C. N. C. Boddy, J. M. Ramanjulu, T.-Y. Yue, S. Natarajan, X.-J. Chu, S. Bräse, F. Rübsam, Chem. Eur. J. 1999, 5, 2584-2601; d) K. C. Nicolaou, C. N. C. Boddy, S. Natarajan, T. Y. Yue, H. Li, S. Bräse, J. M. Ramanjulu, J. Am. Chem. Soc. 1997, 119, 3421-3422.

[6] S. Bräse, Acc. Chem. Res. 2004, 37, 805-816.

[7] Triazene-based polymers have also been used as materials for laserinduced ablation processes. See: a) M. Nagel, R. Hany, T. Lippert, M. Molberg, F. A. Nuesch, D. Rentsch, Macromol. Chem. Phys. 2007, 208, 277-286. b) T. Lippert, Plasma Process. Polym. 2005, 2, 525-546. c) T. Lippert, Adv. Polym. Sci. 2004, 168, 51-246; d) T. Lippert, T. Dickinson, Chem. Rev. 2003, 103, 453-486.

[8] Differential scanning calorimetry has shown that triazenes display a higher thermal stability than diazonium salts. See: a) C. Schotten, S. K. Leprevost, L. M. Yong, C. E. Hughes, K. D. M. Harris, D. L. Browne, Org.
Process. Res. Dev. 2020, DOI: 10.1021/acs.oprd.0c00162; b) R. Ullich, T. Grewer, Thermochim. Acta 1993, 225, 201-211; c) H. Zollinger, Acc. Chem. Res. 1973, 6, 335-341.

[9] a) M. Lu, B. Chen, T. He, Y. Li, J. M. Tour, Chem. Mater. 2007, 19, 44474453; b) B. Chen, A. K. Flatt, H. Jian, J. L. Hudson, J. M. Tour, Chem. Mater. 2005, 17, 4832-486

[10] J. L. Hudson, H. Jian, A. D. Leonard, J. J. Stephenson, J. M. Tour, Chem. Mater. 2006, 18, 2766-2770.

[11] M. N. Hansen, E. Farjami, M. Kristiansen, L. Clima, S. U. Pedersen, K. Daasbjerg, E. E. Ferapontova, K. V. Gothelf, J. Org. Chem. 2010, 75, 2474-2481.

[12] For Rh-catalyzed C-H functionalization, see: a) D. Wang, S. Cui, Tetrahedron 2016, 72, 2725-2730; b) C. Wang, H. Chen, Z. Wang, J. Chen, Y. Huang, Angew. Chem. Int. Ed. 2012, 51, 7242-7245. For C-H activation reactions of aryl triazenes with organosilver compounds, see: c) A. Hafner, T. J. Feuerstein, S. Bräse, Org. Lett. 2013, 15, 3468-3471; d) A. Hafner, S. Bräse, Angew. Chem. Int. Ed. 2012, 51, 3713-3715. For C-X magnesiation-functionalization of halo-substituted triazenes, see: e) C.-Y. Liu, P. Knochel, J. Org. Chem. 2007, 72, 7106-7115.

[13] For selected examples, see: a) M. R. Gyton, A. R. Leverett, M. L. Cole, A. I. McKay, Dalton Trans. 2020, 49, 5653-5661; b) J. P. CamarenaDíaz, A. L. Iglesia, D. Chávez, G. Aguirre, D. B. Grotjahn, A. L. Reingold, M. Parra-Hake, V. Miranda-Soto, Organometallics, 2019, 38, 844-851; c) D. Kalden, S. Kriek, H. Görls, M. Westerhausen, Eur. J. Inorg. Chem. 2018, 4361-4369; d) T. Beweries, F. Reiß, J. Rothe, A. Schulz, A. Villinger, Eur. J. Inorg. Chem. 2019, 1993-1998; e) A. I. McKay, M. L. Cole, Dalton Trans. 2019, 48, 2948-2952; f) D. Kalden, S. Kriek, H. Görls, M. Westerhausen, Dalton Trans. 2015, 44, 8089-8099; g) A. G. M. Barrett, M. R. Crimmin, Michael S. Hill, P. B. Hitchcock, G. Kociok-Köhn, P. A. Procopiou, Inorg. Chem. 2008, 47, 7366-7376.

[14] Triazenes in cancer treatment: a) A. P. Francisco, E. Mendes, A. R. Santos, M. J. Perry, Curr. Pharm. Des. 2019, 25, 1623-1642; b) G. Dresemann, OncoTargets Ther. 2010, 3, 139-146; c) F. Marchesi, M. Turriziani, G. Tortorelli, G. Avvisati, F. Torino, L. De Vecchis, Pharmacol. Res. 2007, 56, 275-287; Veterinary triazene drugs: d) A. S. Peregrine, M. Mamman, Acta Trop. 1993, 54, 185-203 ; e) D. D. Whitelaw, I. R. Bell, P. H. Holmes, S. K. Moloo, H. Hirumi, G. M. Urquhart, M. Murray, Vet. Rec. 1986, 118, 722-726.

[15] R. L. Svec, L. Furiassi, C. G. Skibinski, T. M. Fan, G. J. Riggins, P. J. Hergenrother, ACS Chem. Biol. 2018, 13, 3206-3216.

[16] R. L. Svec, P. J. Hergenrother, Angew. Chem. Int. Ed. 2020, 59, 18571862.

[17] a) N. Jung, S. Bräse, Angew. Chem. Int. Ed. 2012, 51, 12169-12171. The reaction of acetylide anions with azides gives triazole anions instead of triazenyl anions. For examples, see ref. 40 and : b) M. E. Meza-Aviña, M. K. Patel, C. B. Lee, T. J. Dietz, M. P. Croatt, Org. Lett. 2011, 13, 29842987; c) A. Krasinski, V. V. Fokin, K. B. Sharpless, Org. Lett. 2004, 6, 1237-1240; d) G. S. Akimova, V. N. Chistokletov, A. A. Petrov, Zh. Org. Khim. 1967, 3, 968.

[18] a) G. Kiefer, T. Riedel, P. J. Dyson, R. Scopelliti, K. Severin, Angew. Chem. Int. Ed. 2015, 54, 302-305; b) It is not recommended to isolate lithium aminodiazotates, because they can be explosive in the dry state.

[19] For the use of $\mathrm{N}_{2} \mathrm{O}$ in synthetic chemistry, see: K. Severin, Chem. Soc. Rev. 2015, 44, 6375-6386.

[20] For reviews on ynamides, see: a) G. Evano, B. Michelet, C. Zhang, C. R. Chimie 2017, 20,648-664; b) G. Duret, V. Le Fouler, P. Bisseret, V. Bizet, N. Blanchard, Eur. J. Org. Chem. 2017, 6816-6810; c) G. Evano, C. Theunissen, M. Lecomte Aldrichimica Acta 2015, 48, 59; d) X.-N. Wang, H.-S. Yeom, L.-C. Fang, S. He, Z.-X. Ma, B. L. Kedrowski, H. P. Hsung, Acc. Chem. Res. 2014, 47, 560-578; e) K. A. DeKorver, H. Li, A. G. Lohse, R. Hayashi, Z. Lu, Y. Zhang, R. P. Hsung, Chem. Rev. 2010, 110, 5064-5106; f) G. Evano, A. Coste, K. Jouvin, Angew. Chem. Int. Ed. 2010, 49, 2840-2859.

[21] F. G. Perrin, G. Kiefer, L. Jeanbourquin, S. Racine, D. Perrotta, J. Waser, R. Scopelliti, K. Severin, Angew. Chem. Int. Ed. 2015, 54, 13393-13396.

[22] HX addition: a) S. Xu, J. Liu, D. Hu, X. Bi, Green Chem. 2015, 17, 184187; ketene addition: b) A. L. Kohnen, X. Y. Mak, T. Y. Lam, J. R. Dunetz, R. L. Danheiser, Tetrahedron 2006, 62, 3815-3822; c) R. Pirwerdjan, D. L. Priebbenow, P. Becker, P. Lamers, C. Bolm, Org. Lett. 2013, 15, 
5397-5399; D-A cyclopropane addition: d) W. D. Mackay, M. Fistikci, R. M. Carris, J. S. Johnson, Org. Lett. 2014, 16, 1626-1629. TCNE addition: e) M. Betou, N. Kerisit, E. Meledje, Y. R. Leroux, C. Katan, J.-F. Halet, J.-C. Guillemin, Y. Trolez, Chem. Eur. J. 2014, 20, 9553-9557.

[23] I. R. Landman, E. Acuña-Bolomey, R. Scopelliti, F. Fadaei-Tirani, K. Severin, Org. Lett. 2019, 21, 6408-6412.

[24] L. N. Jeanbourquin, R. Scopelliti, F. Fadaei Tirani, K. Severin, Org. Lett. 2017, 19, 2070-2073.

[25] L. N. Jeanbourquin; R. Scopelliti, F. Fadaei Tirani, K. Severin, Helv. Chim. Acta 2017, 100, e1700186.

[26] J.-F. Tan, C. T. Bormann, F. G. Perrin, F. M. Chadwick, K. Severin, N. Cramer, J. Am. Chem. Soc. 2019, 141, 10372-10383.

[27] a) S.-S. Li, L. Qin, L. Dong, Org. Biomol. Chem. 2016, 14, 4554-4570; b) G. Song, F. Wang, X. Li, Chem. Soc. Rev. 2012, 41, 3651-3678; c) J. Wencel-Delord, F. W. Patureau, F. Glorius, Top. Organomet. Chem. 2016, 55, 1-27; d) T. Satoh, M. Miura, Chem. Eur. J. 2010, 16, 1121211222.

[28] T. Wezeman, R. Scopelliti, F. Fadaei-Tirani, K. Severin, Adv. Synth. Catal. 2019, 361, 1383-1388.

[29] J.-F. Tan, C. T. Bormann, K. Severin, N. Cramer, ACS Catal. 2020, 10 , 3790-3796.

[30] L. Zeng, Z. Lai, C. Zhang, H. Xie, S. Cui, Org. Lett. 2020, 22, 2220-2224

[31] a) O. Dimroth, Chem. Ber. 1903, 36, 909-913; b) O. Dimroth, Chem. Ber. 1905, 38, 670-688; c) O. Dimroth, Chem. Ber. 1906, 39, 3905-3912.

[32] W. M. Jones, F. W. Miller, J. Am. Chem. Soc. 1967, 89, 1960-1962.

[33] G. S. Akimova, I. G. Kolokol'tseva, V. N. Chistokletov, A. A. Petrov, Zh. Org. Khim. 1968, 4(6), 954-958.

[34] F. W. Miller, The use of triazenes as vinyl cation precursors, $\mathrm{PhD}$ thesis 1966, University of Florida. Link: https://ufdc.ufl.edu/AA00040923/00001

[35] G. Gaudiano, C. Ticozzi, A. Umani-Ronhi, P. Bravo, Gazz. Chim. Ital. 1967, 97, 1411-1422.

[36] a) A. Hassner, B. A. Belinka, J. Am. Chem. Soc. 1980, 102, 6185-6186; b) A. Hassner, P. Munger, B. A. Belinka, Tetrahedron Lett. 1982, 23, 699-702.

[37] D. W. Farnsworth, B. Pruski, R. H. Smith, J. Org. Chem. 1995, 60, 46414643.

[38] For examples, see: a) J. Zhou, J. He, B. Wang, W. Yang, H. Ren, J. Am Chem. Soc. 2011, 133, 6868-6870. b) ref. 36b.

[39] a) R. H. Smith, C. J. Michejda, Synthesis 1983, 476-477. b) D. H. Sieh, C. J. Michejda, J. Am. Chem. Soc. 1981, 103, 442-445. c) D. H. Sieh, D. J. Wilbur, C. J. Michejda, J. Am. Chem. Soc. 1980, 102, 3883-3887. d) W. M. Jones, D. D. Maness, J. Am. Chem. Soc. 1970, 92, 5457-5464 e) W. M. Jones, D. D. Maness, J. Am. Chem. Soc. 1969, 91, 4314-4315.

[40] A. A. Suleymanov, R. Scopelliti, F. Fadaei Tirani, K. Severin, Org. Lett. 2018, 20, 3323-3326.

[41] For recent examples, see: a) M. J. Hensinger, N. J. Dodge, M. Brewer, Org. Lett. 2020, 22, 497-500; b) S. Cleary, M. Hensinger, M. Brewer, Chem. Sci. 2017, 8, 6810-6814; X-ray structure of a vinyl diazonium salt: c) R. Glaser, G. S. Chen, C. L. Barnes, Angew. Chem., Int. Ed. 1992, 31, 740-743; for reviews, see: d) K. Bott, Chem. Ber. 1994, 127, 933-939; e) K. Bott, Angew. Chem., Int. Ed. 1979, 18, 259-265.

[42] a) C. C. Lee, C. A. Obafemi, Can. J. Chem. 1981, 59, 1636-1640; b) C. C. Lee, E. C. F. Ko, Can. J. Chem. 1976, 54, 3041-3044; c) C. C. Lee, A. J. Cessna, B. A. Davis, M. Oka, Can. J. Chem. 1974, 52, 2679-2683.

[43] a) M. Niggemann, S. Gao, Angew. Chem. Int. Ed. 2018, 57, 1694216944; b) S. Popov, B. Shao, A. L. Bagdasarian, T. R. Benton, L. Zhou, Z. Yang, K. N. Houk, H. M. Nelson, Science 2018, 361, 381-387; d) P. A. Byrne, S. Kobayashi, E.-U. Würthwein, J. Ammer, H. Mayr, J. Am. Chem. Soc. 2017, 139, 1499-1511.

[44] For examples, see: a) J. W. J. van Dorp, G. Lodder, J. Org. Chem. 2008 73, 5416-5428; b) T. Kitamura, S. Kobayashi, H, Tanigchi, Z. Rappoport, J. Org. Chem. 1982, 47, 5003-5009.

[45] For selected recent examples, see: a) D. Kaiser, L. F. Veiros, N. Maulide, Chem. Eur. J. 2016, 22, 4727-4732; b) L. Fu, M. Niggemann, Chem. Eur. J. 2015, 21, 6367-6370; c) F. Zhang, S. Das, A. J. Walkinshaw, A. Casitas, M. Taylor, M. G. Suero, M. J. Gaunt, J. Am. Chem. Soc. 2014, 136, 8851-8854. d) A. J. Walkinshaw, W. Xu, M. G. Suero, M. J. Gaunt J. Am. Chem. Soc. 2013, 135, 12532-12535.
[46] D. Kossler, F. G. Perrin, A. A. Suleymanov, G. Kiefer, R. Scopelliti, K. Severin, N. Cramer, Angew. Chem. Int. Ed. 2017, 56, 11490-11493.

[47] a) M. Hanak, E. J. Carnahan, A. Krowczynski, W. Schoberth, L. R. Subramanian, K. Subramanian, J. Am. Chem. Soc. 1979, 101, 100-108; b) P. J. Stang, Z. Rappoport, M. Hanack, L. R. Subramanian, Vinyl Cations, Academic Press, New York, 1979

[48] A. A. Suleymanov, R. Scopelliti, F. Fadaei Tirani, K. Severin, Adv. Synth. Catal. 2018, 360, 4178-4183.

[49] C. T. Bormann, F. G. Abela, R. Scopelliti, F. Fadaei-Tirani, K. Severin, Eur. J. Org. Chem. 2020, 14, 2130-2139.

[50] For selected reviews, see: a) D. D. La, S. V. Bhosale, L. A. Jones, S. V. Bhosale, ACS Appl. Mater. Interfaces 2018, 10, 12189-12216; b) Mei, N. L. C. Leung, R. T. K. Kwok, J. W. Y. Lam, B. Z. Tang, Chem. Rev. 2015 , $115,11718-11940$.

[51] A. A. Suleymanov, M. Doll, A. Ruggi, R. Scopelliti, F. Fadaei-Tirani, K. Severin, Angew. Chem. Int. Ed. 2020, 59, 9957-9961.

[52] A. A. Suleymanov, E. Le Du, Z. Dong, B. Muriel, R. Scopelliti, F. FadaeiTirani, J. Waser, K. Severin, Org. Lett. 2020, 22, 4517-4522.

[53] For selected examples, see: a) R. Wang, J. R. Falck, Org. Chem. Front 2014, 1, 1029-1034; b) A.-F. Voica, A. Mendoza, W. R. Gutekunst, J. O. Fraga, P. S. Baran, Nat. Chem. 2012, 4, 629-635.

[54] a) F. Mo, D. Qui, Y. Zhang, J. Wang, Acc. Chem. Res. 2018, 51, 496506; b) D. Koziakov, G. Wu, A. J. von Wangelin, Org. Biomol. Chem. 2018, 16, 4942-4953. 


\section{Entry for the Table of Contents}

\begin{tabular}{|l|l|} 
Alkynyl Triazenes \\
Vinyl Triazenes
\end{tabular}

Vinyl and alkynyl triazenes have emerged as highly versatile reagents in organic synthesis. The electron-donating character of the triazene function activates the triple bond of alkynyl triazenes, thereby facilitating addition, cyclization, annulation and rearrangement reactions. Vinyl triazenes, on the other hand, are convenient precursors for vinyl cations, and they can be converted via addition reactions into alkyl triazenes.

Institute and/or researcher Twitter usernames: @kay_severin, @Abdusalom

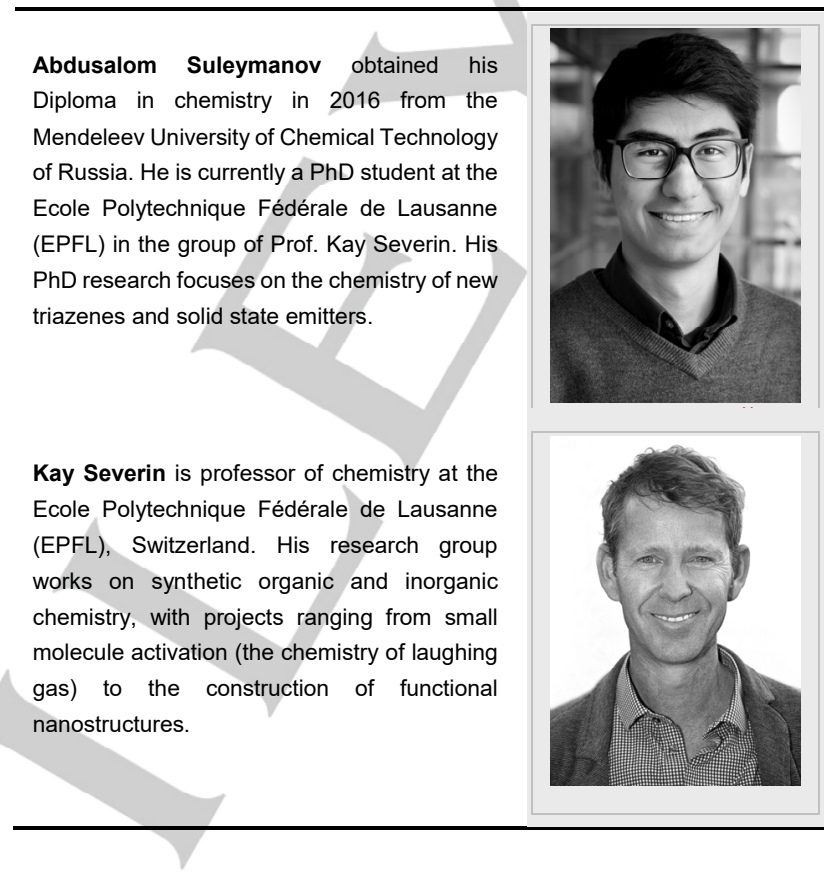




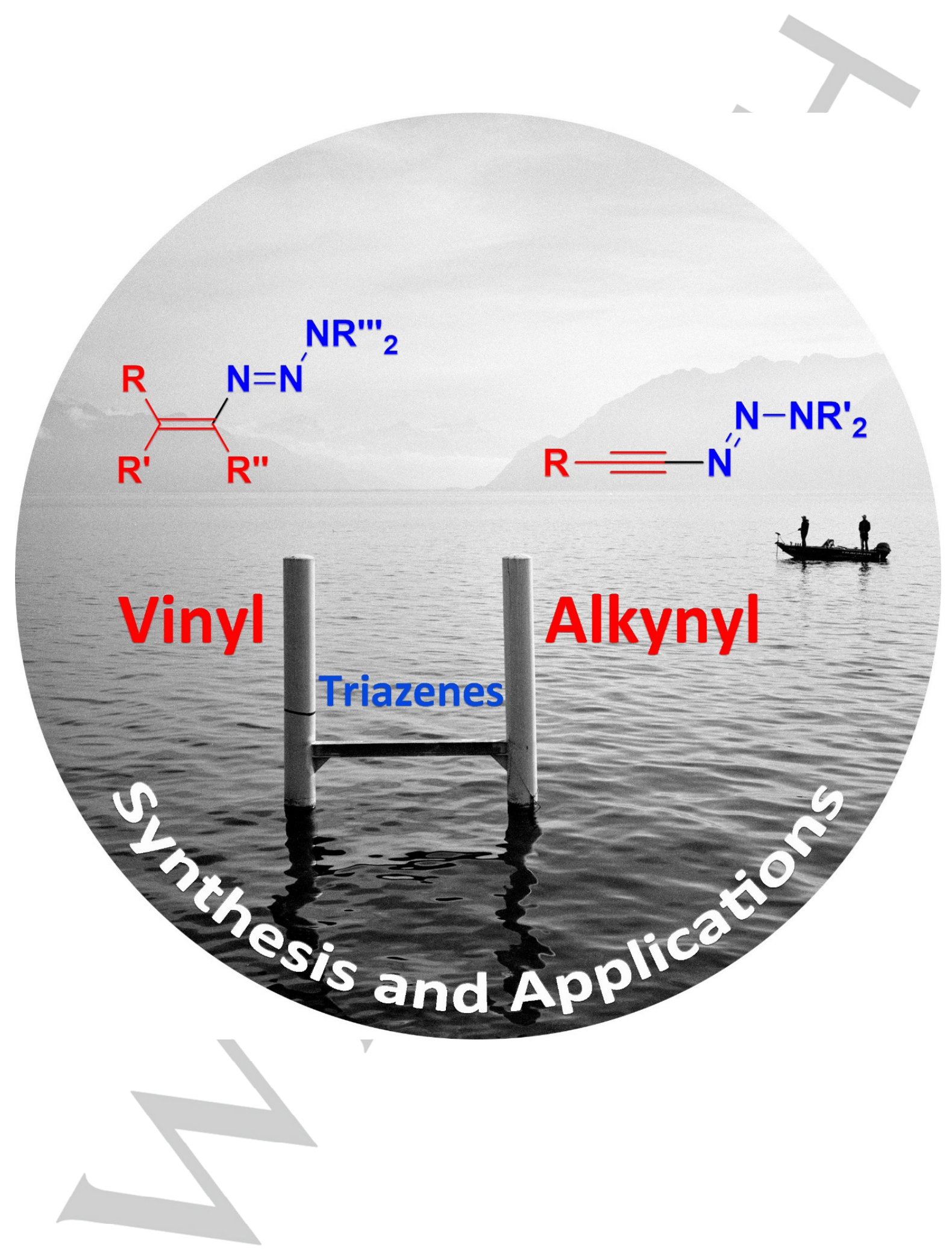

